\title{
Dynamic interactions between spatial change and travel behavior variation in old town fringe
}

\author{
Wenzhu Zhou \\ School of Architecture \\ Southeast University \\ zwz-1234567@163.com

\section{Nan Wang \\ School of Architecture \\ Southeast University \\ Wangnan1230@seu.edu.cn}

\author{
Qiao Li \\ School of Architecture \\ Southeast University \\ liqiao@seu.edu.cn
}

\author{
Qi Wang \\ School of Architecture \\ Southeast University \\ wangqi180061@seu.edu.cn
}

\author{
Zhibin Li \\ School of Transportation \\ Southeast University \\ lizhibin@seu.edu.cn
}

\begin{abstract}
Old town fringe area is changing in its spatial features, and these changes correspondingly result in variations in travel behaviors. Taking the spatial characteristics and travel behavior data of the Nanjing Old Town Fringe (OTF) area in 2010 and 2015 as an example, we conducted a comparative study for two years. First, based on the identification of the spatial range of OTF in these two years by using travel data mutation points and the Point of Information (POI) kernel analysis method, the significant change in the OTF area, from marginal areas in 2010 to nonmarginal areas in 2015, was identified. Second, multiple logit models were used to evaluate the impact of the built environment and economic and social attributes of residents on the choice of travel modes, as well as the different impact factors. From the perspective of overall performance, with reference to the behavior of choosing motor vehicle travel, from 2010 to 2015 , the significant correlation of factors in promoting residents to choose walking, cycling or public transit changed. Moreover, there were three different dynamic characteristics of this correlation change: (1) the correlation of factors was significant and stable from 2010 to 2015; (2) the correlation of factors was significant in 2010 but not significant in 2015; (3) the correlation of factors was not significant in 2010 but was significant in 2015. It was found that the correlated factors of fluctuation were mainly social attribute factors, for example, education, gender, age, whether having a driver's license, etc. Therefore, in future research and practice, we need to focus on the impact of stable correlated factors (such as shortest distance to downtown, plot ratio, occupation, etc.) and factors with increasing correlations (such as bus coverage, gender, age, etc.). And the land-mix factor needs to be considered from both vertical and horizontal perspectives. This will have certain significance and help future development of OTF areas.
\end{abstract}

Keywords: Old town fringe (OTF), travel behavior, built environment, travel model, recognition

Copyright 2020 Wenzhu Zhou, Qiao Li, Zhibin Li, Nan Wang \& Qi Wang http://dx.doi.org/10.5198/jtlu.2020.1653

ISSN: 1938-7849 | Licensed under the Creative Commons Attribution - Noncommercial License 4.0

The Journal of Transport and Land Use is the official journal of the World Society for Transport and Land Use (WSTLUR) and is published and sponsored by the University of Minnesota Center for Transportation Studies.

\section{Article history:}

Received: August 12, 2019

Received in revised form:

January 17, 2020

Accepted: February 20, 2020

Available online: November 10, 2020 


\section{$1 \quad$ Introduction}

Recently, with the rapid development and transformation of both society and the economy, urban populations have increased sharply. With the continuous increase in the city's permanent population, old towns ${ }^{1}$ already under high-density development are becoming unbearable. As a result, old towns are constantly removing some of their functions to the old town fringe ${ }^{2}$ (OTF) and periphery areas, which finally forms new towns (see Figure 1) (Zhou, 2003).

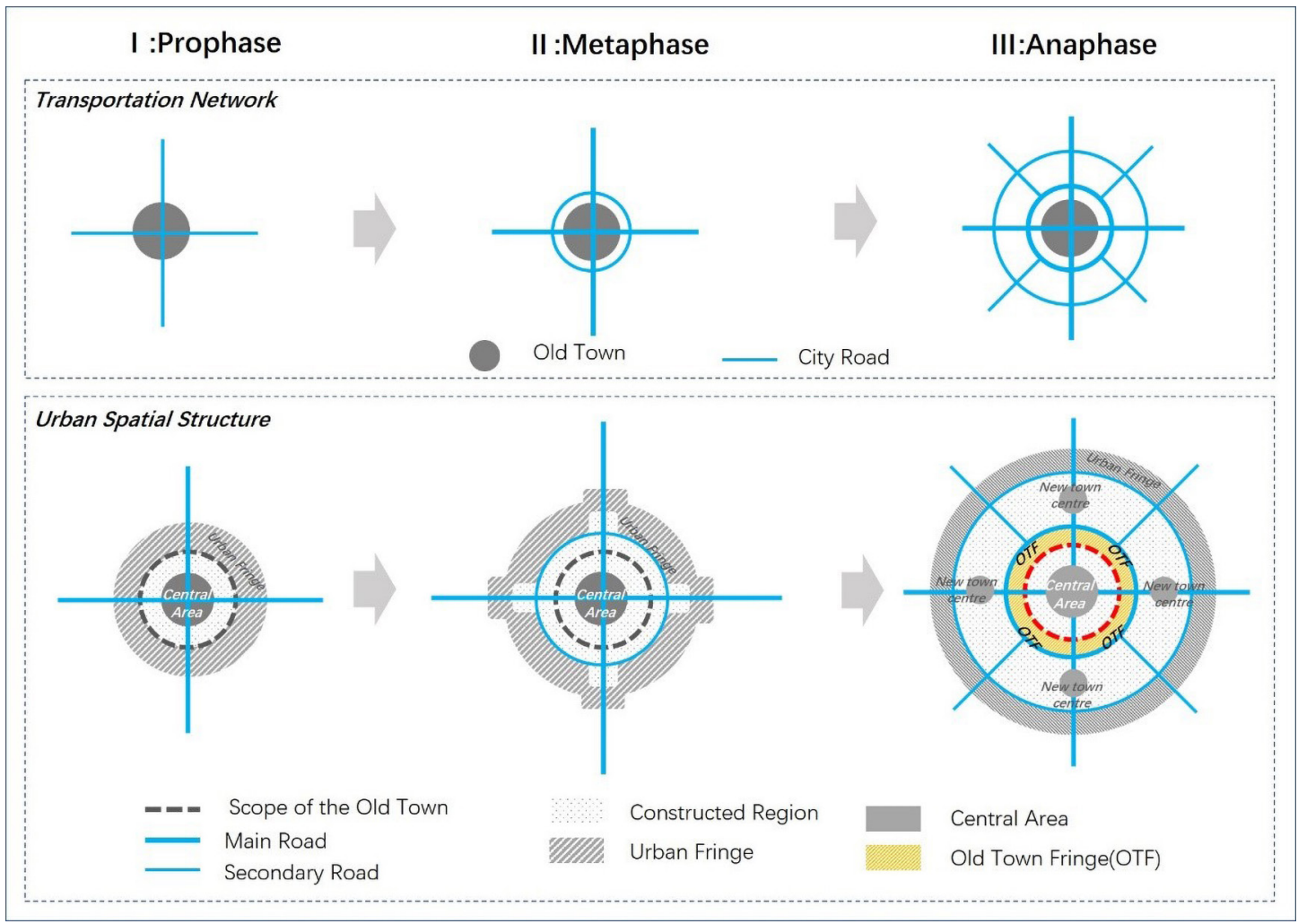

Figure 1. Spatial of the city and the old towns

In general (as shown in the figure), the evolution of the regional structure of a city can be summarized into three stages. First, in the early stage of urban development, the city is bounded by city walls and its development is dominated by internal filling. At this early stage, the city is a typical single center model, and the periphery of the city wall is the urban fringe area. In the second stage, the city begins to cross the city wall and develop outwards; it spreads along the main roads and thus the urban fringe also begins to expand outwards. During this process, new urban fringe areas continue to emerge. Urban inner fringe areas are the first to carry out succession, and they are swallowed up by the city as urban center areas. In the third and final stage, the city has continued to expand and begun to form new towns. At this time, new towns centers develop. Then the secondary centers of cities are formed one after another. The inner fringe area of the city, which was the earliest to carry out succession, now becomes the transi-

${ }^{1}$ The old town in this project refers to the area where the historical city system is preserved, and it is also one of the core areas where the city's historical and cultural, commercial finance, public services, living and other urban functions are concentrated. Historically ancient cities are generally bound within city walls and moats, or urban areas that have witnessed important historical development to date.

${ }^{2} \mathrm{OTF}$ is the area adjacent to the old town. It has the characteristics of overflow of old city functions, mixed land structure and dynamic spatial changes. Same below. 
tion zone between the old town and the new town center. Because of the positive and negative effects on the central area at the same time, the development level of this area is uneven, and it now becomes the fringe area of the old town. In the recent urban spatial structure, the OTF area plays an important role in the connection and transition between the old town and the surrounding new city. It bears the important transfer function of traffic flow between the two sections.

In the process of urban transformation from single center to multi-center, fringe areas that used to be located in the periphery of the old town gradually change from fringe areas to urban center areas. With the old town continuously removing its functions to the OTF, the space of the OTF begins to change. For example, due to urban development and construction, the edge feature of some areas gradually disappears, and thus becomes the core area of the city (Gu \& Chen,1995; Yang \& Xu, 2012). On the other hand, from the point of view of travel characteristics, the spatial transformation of the OTF leads to more complex changes in residents' travel behaviors. Therefore, it is necessary to study the relationship between the spatial change of the OTF and the variation of travel behaviors.

Researchers have achieved much in the study of the relationship between travel behavior and space. However, existing studies mainly focus on neighborhood and regional levels where the built environment has not changed much (Ta, Chai, Zhang, \& Sun, 2017). The OTF, which features a significant change in the built environment, has not yet been comprehensively studied. In an OTF, some areas gradually lose their edge characteristics and become the core areas of the city. In addition, existing studies have mainly used lumped and non-lumped models to study the impact of a built environment on travel behavior in a certain period of time, so as to predict the impact in future years. However, these established models lack the comparative validation of the impact relationship between tracking data and the future years (Zegras, 2010; Sun, 2014; Christian et al., 2017).

Therefore, we have used the old city fringe area in Nanjing with significant changes in the built environment as the research example. Non-aggregate models are employed to track and compare the impact of a built environment on travel behavior from 2010 to 2015.

This paper consists of four parts: (1) mutation point analysis was used to study household survey data and Point of Information (POI) data to identify the boundaries of OTF in 2010 and2015; (2) the OTF-changed-areas in 2010 and 2015 were screened out; (3) multiple logit models were created to describe the impact of built environment and personal socioeconomic attributes on travel behavior these two years, respectively; (4) the difference and changes between the impact factors of the travel behaviors in 2010 and 2015 were compared and the reasons for this difference and changes analyzed.

This study tracks the change of space and travel behavior in the OTF, which is helpful in understanding their variation regulations and strong interactions in a dynamic time. This could ultimately provide important instructions for the sustainable development of this area.

\section{$2 \quad$ Literature review}

\subsection{The built environment and travel behavior}

The boundary of research is mostly bordered by administrative divisions or land-use boundaries, and a built environment shows relatively little change. For example, Cao, Mokhtarian, and Handy (2007) studied the relationship between built environment and travel behavior based on 547 traveler data collected from four traditional neighborhoods and four suburban neighborhoods in northern California. Cervero and Murakami (2010) obtained data on 370 urbanized areas in the United States, based on which he studied the mechanism of impact of built environment and population density on transportation. Lu, Xiao, and Ye (2016) selected 36 housing estates in Hong Kong and divided them into low, medium, and high densities to study the influence of density, diversity, and design on the choice of 
walking. The existing researches show a lack of study on the special fringe area. Due to the significant changes of built environment and development, the characteristics of the fringe disappear, as a result of which such area changes into the core area of the city.

Besides this, although the interaction between travel and land use has always been the focus of research, the existing researches have mostly chosen the survey data of a certain year to analyze. For example, Munshi (2016) used travel survey data from Rajgood, India, in 2012. The conclusion of the study was that residents will choose their way of travel according to the built environment of their residence. In addition, it was found that the mixed degree of destination accessibility and land use had a significant impact on the choice of travel modes in the built environment variables. Although these conclusions provided some significance at that time, their applicability and validity were limited as the data were only from one year. What is lacking in the research design is the continuous observation, tracking, and validation of a dynamic change area (Munshi, 2016; Ye \& Titheridge, 2016; Christian et al., 2017)

In the selection of influencing factors of building environment and travel behavior, the indicators have gradually diversified and become comprehensive. Establishment environment measurement indicators gradually developed from the original "3D” model proposed by Cervero and Kockelman (1997) to the widely accepted "5D" model. The 5D model includes density, diversity, design, accessibility, and transportation facilities convenience. Later, scholars found that, in addition to the built environment, individual travel behavior is also affected by social and economic factors. A large number of empirical studies have proved that social and economic factors such as income, occupation, family size, education background, car ownership, number of children, gender, and age have significant effects on residents' choice of travel mode. For example, Vandersmissen (2003) added age to the study of urban areas in Quebec, Canada. Schwanen, Dieleman, \& Digist (2004) found that under the control of other factors, the annual net income of commuters driving automobiles was positively correlated with commuting time. A study by Manugh, Miranda-Moreno, \& El-Geniedy (2010) of the Montreal metropolitan area in Canada found that the lower the income, the shorter the travel distance. Over the past few years, residents' self-selection factors have been gradually valued and added to the discussion of correlation models (van Wee, 2009; Ettema \& Nieuwenhuis, 2017; Bohte, Maat, \& van Wee, 2009). When selecting travel behavior factors, scholars have mainly focused on the discussion of built environment versus travel distance (Ding, Wang, Liu, Zhang, \& Yang, 2017), vehicle miles traveled, and the impact of mode selection (Bowman \& Ben-Akiva, 2001). Multivariate linear and non-aggregate models are mainly used to build environment and travel behavior impact models.

Generally speaking, existing studies on the impact of travel behavior on space and personal socioeconomic attributes have been more extensive and in-depth, and there is some consensus and relevant conclusions. But these conclusions cannot be directly adapted to such a significant change in a built environment as the OTF. In addition, existing studies have mainly used lumped and non-lumped models to study the impact model of built environment and travel behavior (Maat \& Timmermans, 2009; Schwanen \& Mokhtarian, 2005; Shiftan \& Barlach, 2002) in a certain period of time so as to predict the impact of future years, but a comparative validation of the impact relationship between tracking data and future years is lacking.

\subsection{Old town fringe studies}

Foreign countries initially defined the urban fringe area mainly by experience. For example, J. Friedman classified the area around the city into urban fringe area according to daily commuting range setting the inner fringe area at $10-15 \mathrm{~km}$ and the outer fringe area at $25-50 \mathrm{~km}$. In respect of the development of a city, this qualitative analysis has great limitations. R.E. Pahl (Rong, Guo, \& Zhang, 2011) discussed four features (segregation, selective immigration, commuting, and collapse of geographical and social 
hierarchies) of the urban fringe from a sociological point of view. A variety of quantitative measures have gradually derived from these characteristics. For example, the Indian scholar Ghana used the agglomeration index and suburbanization index to determine the boundaries of the urban fringe, while the Canadian scholar C.B. Bryant used the ratio of non-agricultural population to agricultural population. The Chinese scholar Gu (Gu, Chen, \& Ding, 1993) proposed a method of population density gradient rate analysis in 1993, followed by Chen (1996), who presented a method of fracture point analysis in 1996 when he studied the marginal zone. He selected 20 indicators from five aspects: level, structure, density, connection, and infrastructure, and succeeded in delineating the border areas. Further, some research methods such as the "breakpoint" method and GIS analysis have been successfully applied to recognition practice many times, for example demarcate the elastic growth boundary of cities based on principal component analysis and cluster analysis, taking into consideration comprehensive factors such as ecology, construction conditions, population distribution, economic development, infrastructure, etc. (Wang, Zhang Kang, et al, 2011; Mu, \& Liu, 2010; Wang \& Gu, 2017). However, these research methods mostly reflect the physical or economic characteristics of urban areas from economic statistics of social GDP, population data, land-use data extracted from color TM synthetic image map, etc.

In 2018, the Chinese scholar Zhou (Zhou et al., 2019) proposed a fringe recognition method based on travel behavior. This method is based on ArcGIS platform and multi-metadata, including household survey data and POI data and provided a new perspective for the study of the old town fringe and urban fringe. As the purpose of the current study was mainly to explore the impact mechanism of the choice of travel mode by residents in fringe areas, the interaction between travel and space needs to be understood. Then the application of resident trip survey data to fringe recognition will reflect the interaction between urban space and resident behavior in the special area of OTF. Therefore, this study used this method to identify the boundary area of Nanjing Old Town.

\section{Data and sources}

\subsection{Study area}

Nanjing, the capital of Jiangsu province, located in the east of China, was selected for the case study. The scope of this study is in the main urban area of Nanjing (see Figure 2). Three districts in the central urban area (i.e., Xuanwu, Gulou, and Qinhuai), two districts close to the fringe of the central area (i.e., Yuhua and Jianye) and three suburban districts (i.e., Jiangning, Pukou, and Xianlin) outside of the urban area were also included. The area covered is around $2,964.24 \mathrm{~km}^{2}$, containing 182 traffic analysis zones (TAZ). 

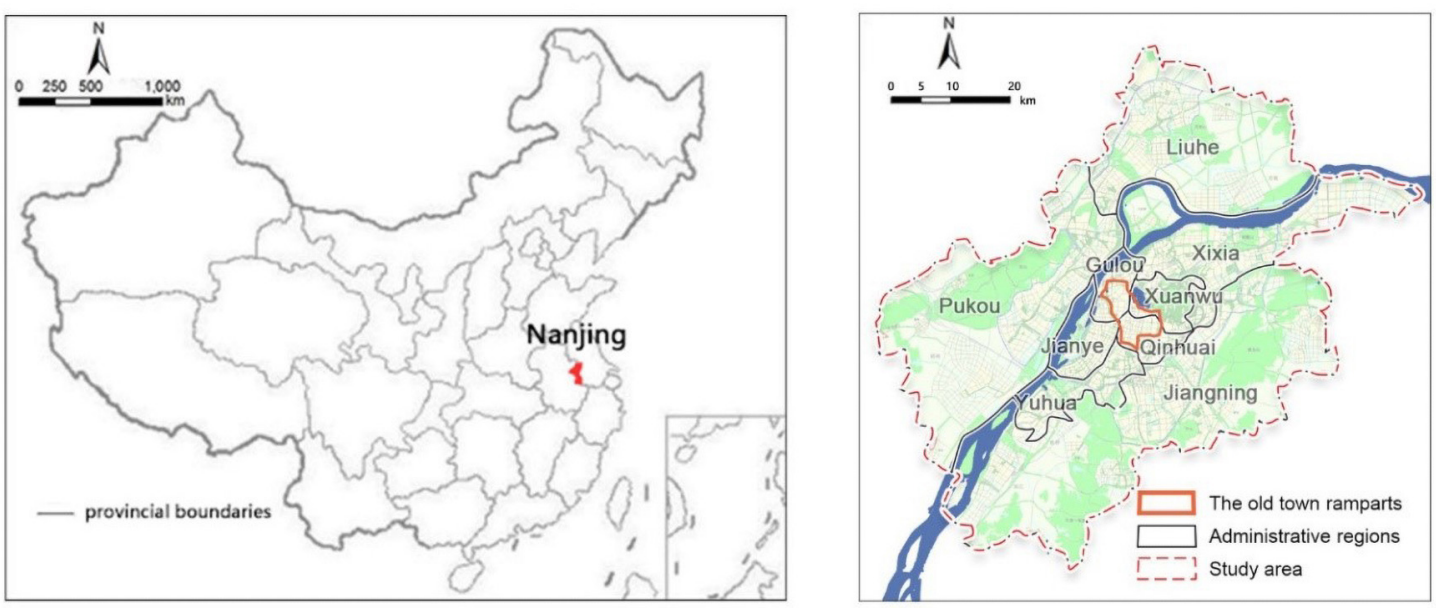

Figure 2. Spatial information of the studied area

\subsection{Household survey data}

Household survey data in the city of Nanjing, China were obtained. In order to reflect the changes in the way residents travel in the past few years, the household survey data of the years 2010 and 2015 were studied. The research team obtained the survey data of Nanjing residents' trips from the Office of the Traffic Planning Leading Group of the Nanjing Planning Bureau. The travel data samples of 2010 and 2015 were taken from a residents' travel survey conducted on a normal working day in December 2010 and December 2015, respectively. A total of 18 questions were designed for the Nanjing Resident Travel Questionnaire, which were divided into four aspects: survey of basic household characteristics, personal characteristics of residents, opinions and suggestions on urban transportation, and records of the survey of residents' first trip. It should be emphasized that the purpose of this study is to comprehensively grasp the basic spatiotemporal distribution of the trips of residents in the main urban area of Nanjing, and to explore the development and change of urban space from the group travel conditions. Household surveys were selected for the survey. The survey communities selected in the past two years were consistent, and the value of the household address was kept repetitive. To ensure the representativeness and stability of the two-year survey respondents. The survey covers three areas in the central urban area (Xuanwu, Gulou, and Qinhuai districts); two areas near the edge of the central urban area (Yuhua and Jianye districts) and four areas in the suburbs (Jiangning, Pukou, Xianlin, and Liuhe districts), with an area of 2,964.24 km². Among them, 2,000 households were randomly surveyed in 2010, with a total of 5,391 people. And finally, 14,586 trip records were obtained. In 2015, a total of 6,041 people from 1999 households were randomly investigated. Finally, 17,568 travel records were obtained. (In 2010, there were around 6.5 million permanent residents in the main urban area of Nanjing, and in 2015, there were 800 permanent residents in the main urban area of Nanjing.) The research aimed to accurately and objectively reflect the relationship between the spatial changes in OTF and the changes in residents' travel behavior.

Compared with 2010, the proportion of walking and bicycling decreased significantly in 2015. In contrast, the proportion of bus and car trips increased to a certain extent, along with the proportion of people with motor vehicles. Urban traffic trips are developing toward high mobility. 


\subsection{POl data}

This study obtained the POI data of Nanjing from the Baidu Map website. POI data are discrete points with spatial coordinates and properties. The agglomeration features of various POI spatial distributions indirectly reflect the distribution features of various public service facilities in the urban space. The spatial distribution difference of POI density can reflect the different development levels of various regions. The POI data generally contain 13 different types, covering business, residents, sports, recreations, administration services, etc.

The process of obtaining POI data consisted of the following four steps: (1) To establish the location of the administrative boundary of Nanjing; the whole Nanjing area was divided into several unit grids, labeling the geographic location of each grid. (2) Login to the API of Baidu Web service and enter the location retrieval service (place API), then select the rectangular area retrieval tool to import the geographic location information of a single grid. (3) A Python code was written to obtain POI data within each cell grid. (4) All of Nanjing's POI data were integrated through geographical calibration and data aggregation.

In order to accurately identify the scope of the old city fringe area and compare the changes in this fringe area over the two years being studied (2010 and 2015), Baidu POI data in Nanjing were collected for both years. Through the coordinate system transformation and the spatial registration, 228278 POI data of year 2010 and 289134 POI data of 2015 were successfully obtained. The POI data used in this study cover eight administrative districts in the main urban area of Nanjing in terms of spatial distribution, which was the same as the scope covered by the household survey. The number of POI data of each category and their proportions in the total data are described in Table 1. Among them, business accounts for nearly half of the major POIs, followed by traffic facility, science, and education. Nuclear density analysis was conducted to show the clustering degree of various data points. In this way, the distributions and spatial structures of various facilities in the main urban area can be discovered.

Table 1. Description of Baidu POI data characteristics

\begin{tabular}{|lllll|}
\hline Variable & Frequency & Percent & Frequency & Percent \\
\cline { 2 - 5 } & $\mathbf{2 0 1 0}$ & $\mathbf{2 0 1 5}$ & 49149 & $17.00 \%$ \\
\hline Catering Services & 49148 & $21.50 \%$ & 11 & $0.00 \%$ \\
\hline Tourist Attraction & 11 & $0.01 \%$ & 44115 & $15.26 \%$ \\
\hline Corporate Business & 44116 & $19.33 \%$ & 72448 & $25.06 \%$ \\
\hline Shopping Services & 9999 & $4.39 \%$ & 23612 & $8.17 \%$ \\
\hline Traffic Facilities & 23612 & $10.35 \%$ & 6541 & $2.26 \%$ \\
\hline Finance and Insurance & 6541 & $2.86 \%$ & 15110 & $5.23 \%$ \\
\hline Science and Education & 15111 & $6.63 \%$ & 10229 & $3.54 \%$ \\
\hline Serviced Apartment & 10231 & $4.48 \%$ & 46982 & $16.25 \%$ \\
\hline Commercial Services & 49570 & $21.71 \%$ & 48 & $0.02 \%$ \\
\hline Sports and Recreation & 48 & $0.04 \%$ & 5728 & $1.98 \%$ \\
\hline Medical Care & 5728 & $2.51 \%$ & 9286 & $3.21 \%$ \\
\hline $\begin{array}{l}\text { Government agencies } \\
\text { and social organizations }\end{array}$ & 9286 & $4.07 \%$ & 5875 & $2.03 \%$ \\
\hline $\begin{array}{l}\text { Accommodation } \\
\text { Services }\end{array}$ & 4877 & $2.14 \%$ & & \\
\hline
\end{tabular}




\subsection{Built environmental indicators data}

Built environment data were measured via the 5D (Density, Design, Diversity, Destination Accessibility, and Distance-to-transit) technique (see Table 2). Density includes building density, plot ratio and road network density. Diversity includes land-use diversity, land-use mix and job-housing ratio. The number of signal-controlled intersections was selected as the indicator for design. Destination accessibility utilizes straight-line distance and shortest distance to the downtown area. The distance-to-transit index includes subway coverage (within 1,000 meters of the subway station) and bus coverage (within 300 meters of the bus station). The specific meanings and calculation methods for each indicator are summarized in Table 2. The built environment data were obtained mainly based on the land-use status data (see Figure 3).

Table 2. Description of built environment variables

\begin{tabular}{|c|c|c|}
\hline Built environment variable & & Measurement description \\
\hline \multirow[t]{3}{*}{ Density } & Building Density & $\begin{array}{l}\text { Building Density }=S_{b i} / S_{i} \text {. The sum of the building base area in } \\
\text { the i TAZ } S_{b i} \text { and the area of i TAZ Si is calculated by the build- } \\
\text { ing status diagram }\end{array}$ \\
\hline & Plot Ratio & $\begin{array}{l}\text { Plot Ratio }=S_{\mathrm{Bi}} / S_{\mathrm{i}} \text {. The building area } \mathrm{SBi} \text { in each TAZ is calcu- } \\
\text { lated by the building status diagram }\end{array}$ \\
\hline & $\begin{array}{l}\text { Road Network } \\
\text { Density }\end{array}$ & $\begin{array}{l}\text { Road Network Density }=\mathrm{L}_{\mathrm{i}} / \mathrm{S}_{\mathrm{i}} \text {. Road length } \mathrm{L}_{\mathrm{i}} \text { in the } \mathrm{i} \text { TAZ is } \\
\text { calculated by the land-use status chart. }\end{array}$ \\
\hline \multirow[t]{5}{*}{ Diversity } & $\begin{array}{l}\text { Land-Use Di- } \\
\text { versity }\end{array}$ & $\begin{array}{l}\text { Land-Use Diversity is represented by the number of land-use } \\
\text { types in each TAZ, calculated by the land-use status map. }\end{array}$ \\
\hline & Land-Use Mix & $\begin{array}{l}\text { The number of land-use types of the } \mathrm{i} \text { TAZ } \mathrm{K}_{\mathrm{i}} \text { is calculated by } \\
\text { the land-use status map } \cdot \mathrm{p}_{\mathrm{k}, \mathrm{i}} \text { represent the proportion of land area } \\
\text { in category } \mathrm{K} \text { of the } \mathrm{i} \text { TAZ. }\end{array}$ \\
\hline & & Land Use $\mathrm{Mix}_{\mathrm{i}}=\frac{-\sum_{\mathrm{K}=1}^{\mathrm{K}} \mathrm{p}_{\mathrm{k}, \mathrm{i}} \ln \left(\mathrm{p}_{\mathrm{k}, \mathrm{i}}\right)}{\ln (\mathrm{K}, \mathrm{i})}$ \\
\hline & & The larger the value, the more mixed the land is. \\
\hline & Job-housing Ratio & $\begin{array}{l}\text { Job-housing Ratio }=\left(A_{i}+B_{i}+M_{i}\right) / R_{i} \cdot A_{i}, B_{i}, M_{i}, R_{i} \text { represent } \\
\text { the area of commercial land }(A) \text {, office land }(B) \text {, industrial land } \\
(M) \text { and residential land }(R) \text { in i TAZ. }\end{array}$ \\
\hline Design & $\begin{array}{l}\text { Number of } \\
\text { Signal-controlled } \\
\text { Intersections }\end{array}$ & $\begin{array}{l}\text { The number of signal-controlled intersections of each TAZ is } \\
\text { calculated by topographic map. }\end{array}$ \\
\hline \multirow[t]{2}{*}{ Destination Accessibility } & $\begin{array}{l}\text { Straight-line } \\
\text { Distance }\end{array}$ & $\begin{array}{l}\text { Straight-line distance to the downtown area is calculated by Baidu } \\
\text { Map. }\end{array}$ \\
\hline & Shortest Distance & $\begin{array}{l}\text { The shortest distance to the downtown area is calculated by Baidu } \\
\text { Map. }\end{array}$ \\
\hline \multirow[t]{2}{*}{ Distance to transit } & Bus Coverage & $\begin{array}{l}\text { Bus Coverage uses POI of bus station to operate } 300 \mathrm{~m} \text { buffer, } \\
\text { and overlap with TAZ range. }\end{array}$ \\
\hline & Subway Coverage & $\begin{array}{l}\text { Subway Coverage uses POI of bus station to operate } 1000 \mathrm{~m} \text { buf- } \\
\text { fer, and overlap with TAZ range. }\end{array}$ \\
\hline
\end{tabular}



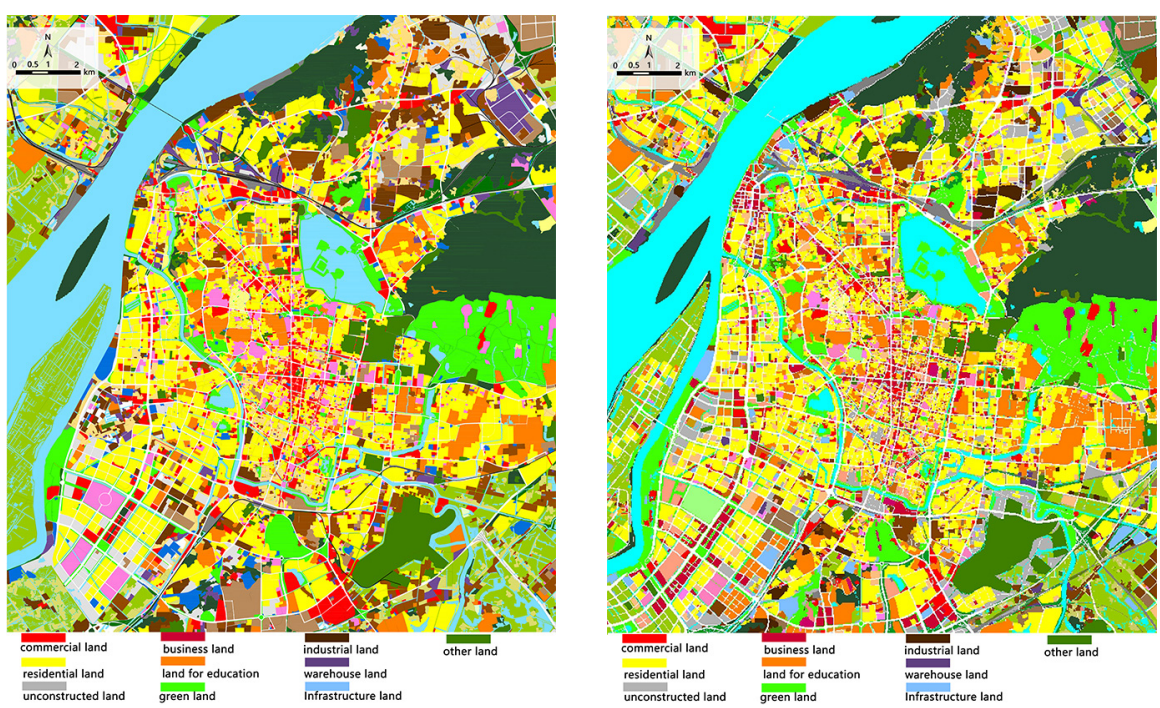

Figure 3. Land-use map of Nanjing (left: 2010; right: 2015)

\section{$4 \quad$ Methods}

This research mainly uses sample questionnaire surveys and quantitative analysis. The data analysis mainly uses logistic regression analysis. Such methods have become the main method for studying the relationship between urban residents' travel and space in China, and are being widely used (Lawrence, Schmid, Sallis, Chapman, \& Saelens, 2004; Handy, Boarnet, Ewing, \& Killingsworth, 2002; Naveen, Vincent, \& Ahmed, 2002; Khan, Maoh, Lee, \& Anderson, 2014; Wei, Yu, De, et al., 2012). This study is divided into two sections: the identification of the OTF and the study of travel behavior. In the identification of the OTF, the effective boundary of the OTF was obtained by the method of mutation point analysis based on the survey data of resident trips and POI data from the network map. Accordingly, the dynamic evolution area of the OTF was found. Then as for the changed area, the relationship model between the travel mode and the built environment and individual economic and social attributes were established separately for 2010 and 2015.The relationship between residents' travel behavior changes and spatial changes in the OTF-changed area was deeply analyzed in order to understand the changing mechanism of the complex travel in this complex space.

\subsection{Identification of the old town fringe area}

With the gradual multi-source acquisition of data in recent years, many new technical methods have been applied to spatial recognition. For example, multi-view learning, ensemble empirical mode decomposition from Google Earth, and judgment of data mutation intervals (Chen, et al., 2019; Chen et al., 2018). Each of these methods has advantages and a suitable research environment. This study selected a method for spatial recognition of the fringe area of the old city based on the perspective of travel proposed by scholar Zhou (2018) as it is most relevant in the context of the study. Referring to Zhou's method, the research views each TAZ as a region with different influence and attraction. With an increase in distance, the impact of the city center on its subordinate areas decreases. The influence of the city center is eventually replaced by the impact of other nearby cities or regions. Theoretically, there are two mutation points in the range from the core area of the old city to its influence area; one is the inner mutation point, the other is the external mutation point. 
The first step was to match residents' daily travel data with the corresponding spatial data. The average travel intensity of each traffic area was calculated by formula (1) and visualized by ArcGIS.

$$
\mathrm{T}_{i}=\frac{\mathrm{t}_{v}}{\mathrm{t}_{a}}
$$

where $T_{i}, \mathrm{t}_{v}$ and $\mathrm{t} a$, are traffic intensity, traffic volume, and traffic area, respectively.

The second step was to extract the mutation point and the mutation interval of travel intensity. By setting the old town core as the center, variations of travel intensity in 36 directions were extracted. The distance interval with the largest $\mathrm{Vi}$ is the mutation interval of travel intensity. Based on the variation of travel distance, the mutation interval of each direction was determined. According to the mutation point theory, two mutation points of traffic intensity are judged, on which the inner and outer boundaries of the old city fringe can then be determined.

The third step was to verify the results by POI data. In ArcGIS, the weighted kernel density analysis was performed, and the density decay contour of POI points obtained. By checking the coincidence between the mutation interval of POI and the travel intensity interval, the range of the old city fringe area was finally identified, and the mismatches eliminated. From this we can ultimately find the spatial range of the OTF.

\subsection{Determining the changes of old town fringe and establishing database}

With the continued development of the city, parts of the OTF space have changed and the fringe is no longer the fringe. This study defines these areas as the OTF-changed-areas.

Firstly, based on the delineated range of the OTF in 2010 and 2015, the range of the OTFchanged-area is determined. The corresponding travel data in 2010 and 2015 were collected, after which the POI data of this area were screened out in ArcGIS. Using the spatial link function in ArcGIS, the POI data and land-use status data were combined. According to the table, the related indicators of the built environment in each TAZ were calculated. After the successful matching of the built environment data and travel data, a database of the OTF-changed area was established. Each travel sample includes three main data: (1) travel data: OD information, travel mode, travel time, etc.; (2) personal socioeconomic attributes: age, gender, driving license, education, occupation, etc.; (3) built environment data of the departure place: 5D indicators of the TAZ where the departure place is located.

\subsection{Model development}

In order to study the impact of built environment and individual socioeconomic attributes on the choice of travel modes of residents in the old city fringe, quantitative inspection was conducted on the basis of data spatial visualization and statistical analysis. The travel modes were divided into three categories: walking and cycling, public transportation, and motor vehicle. The multiple logit model was used to analyze the data.

$\operatorname{Logit}(\mathrm{P} 1 / \mathrm{P} 2)=\beta 0+\beta 1 \mathrm{X} 1+\beta 2 \mathrm{X} 2+\varepsilon$

In order to study the impact of built environment on different travel modes more specifically, the motor vehicle was used as the reference for walking and cycling, and public transport. Equations (3) and (4) are built on the basis of formula (2) for regression analysis. 
$\operatorname{Logit}(\mathrm{PW} \& \mathrm{~B} / \mathrm{PM})=\beta 0+\beta 1 \mathrm{X} 1+\beta 2 \mathrm{X} 2+\varepsilon$

$\operatorname{Logit}(\mathrm{PT} / \mathrm{PM})=\beta 0+\beta 1 \mathrm{X} 1+\beta 2 \mathrm{X} 2+\varepsilon$

Logit (P1/P2) is the natural logarithm of the probability ratio of any two commuting modes. $\varepsilon$ is the random error term. X1 is the built environment characteristics of residential areas, covering the five dimensions of density, diversity, design, distance-to-transit, and destination accessibility. Specific indicators including building density, volume ratio, road network density, land diversity, degree of land mix, occupation living ratio, number of intersections controlled by traffic lights, straight-line distance to city center, bypass coefficient, bus station, and subway station coverage were considered in X1. X2 comprises the socioeconomic attributes of residents, including gender, age, occupation, driver's license, and education level. $\beta \mathrm{t}(\mathrm{t}=0,1,2)$ are the fitting parameters.

The OTF-changed-areas in 2010 and 2015 were separately modeled and analyzed, and both significant and non-significant indicators of each year were obtained. In terms of level of significance, the indicators were divided into three categories: very significant $\left.{ }^{* * *}\right)$, significant $\left(^{(* *}\right)$, and general significant $\left(^{*}\right)$, after which a comparative analysis between 2010 and 2015 was conducted. The core objective was to understand the interactions among the space, population, and travel mode in the marginal evolution area, and explain the intrinsic mechanism and reasons.

\section{$5 \quad$ Results}

\subsection{Recognition results of OTF}

The distribution of travel intensity in 2010 is shown in Figure 4. The study found that the overall travel intensity of the old town is the highest, with a downward trend from the center to suburban areas. In close vicinity to the Nanjing city wall, there is a transitional zone where the intensity is obviously lower. There are several areas surrounding the old town with higher travel intensity: Hexi, Chengnan, Xinzhuang, Pukou, and Jiangning. These are the rising sub-centers of Nanjing. This phenomenon still exists in the travel intensity distribution map in 2015 (see Figure 4). From the map, we can see that the travel intensity of the center of old town has decreased, but the spatial structure of the strong center is still obvious. The kernel density of POI data was then analyzed by ArcGIS for each year. Figure 5 shows the results. Finally, a superposition check of the mutation interval was performed to determine the range of the old city fringe in 2010 and 2015, respectively (see Figures 6 and 7). 

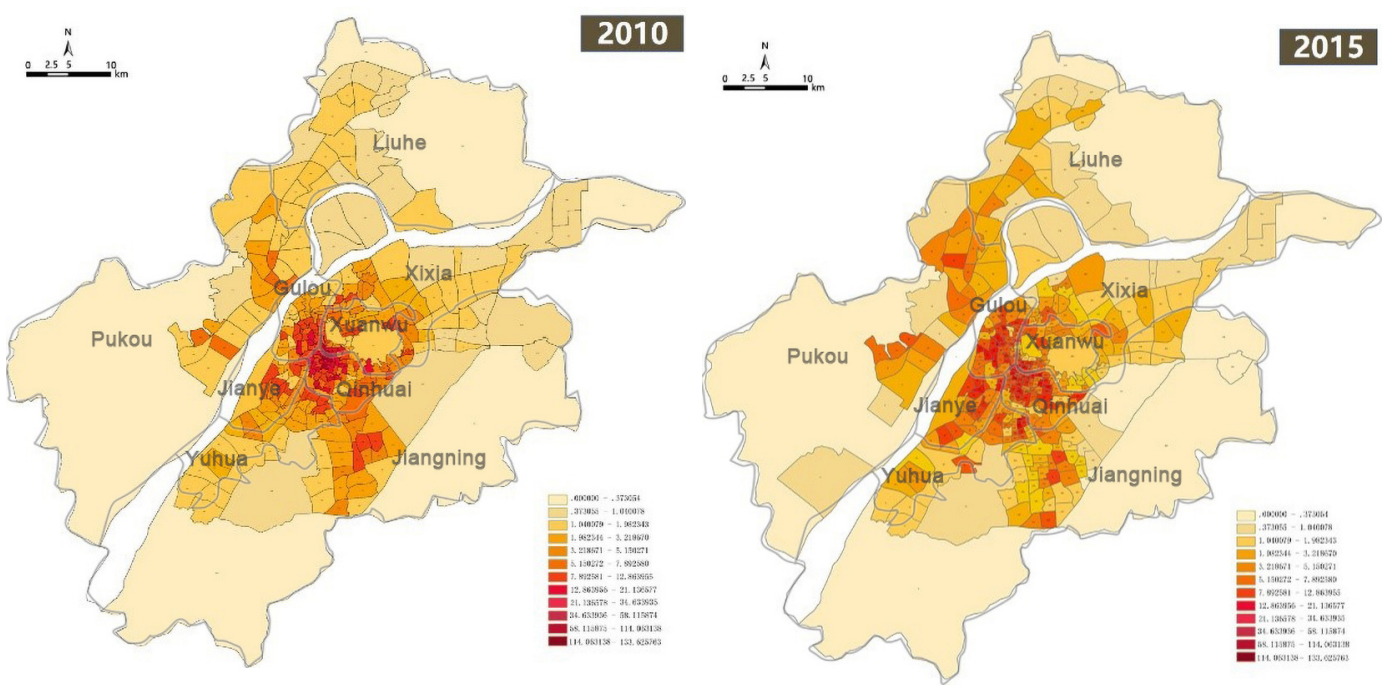

Figure 4. The travel identity distribution map of 2010 and 2015
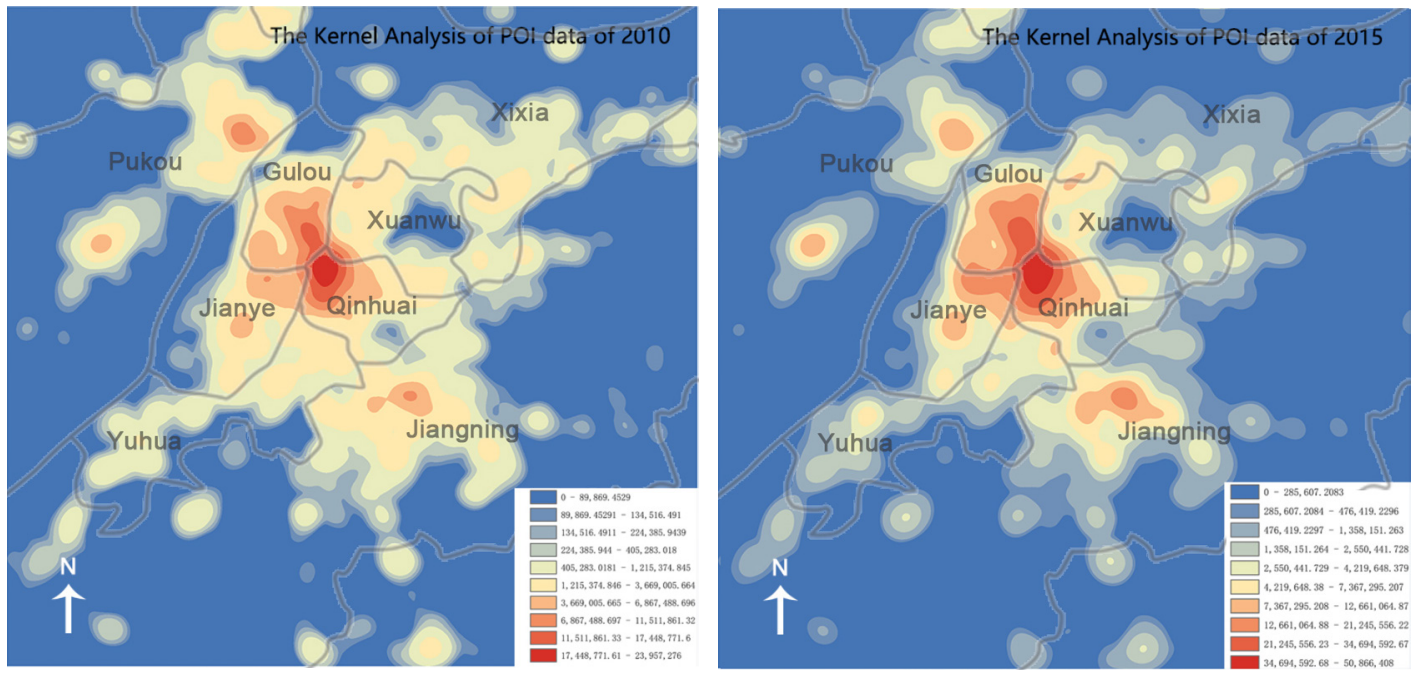

Figure 5. The kernel analysis of POI data of 2010 and 2015

In 2010 and 2015, the recognition results of the OTF clearly show the development of the OTF and changes in boundary. Through comparison, some characteristic changes of the OTF can be found.

(a) On the spatial distribution, the OTF is uneven and irregular. From 2010 to 2015, the OTF is always close to the Nanjing Ming Dynasty city wall. So, the boundary of the OTF is highly consistent with the old town boundary. In 2010, the OTF showed a belt distribution around the old town, while in 2015, some faults and fragments appeared.

(b) On scale, the OTF began to shrink. In 2010, the OTF covered $42 \mathrm{TAZ}$ with an area of 46.56 $\mathrm{km}$. In 2015 , only $20 \mathrm{TAZ}$ were covered, with an area of $24.97 \mathrm{~km}$. In the past five years, the overall area of the OTF has decreased by $46.37 \%$, indicating that the evolution speed is much faster.

We overlaid the two years' OTF (see Figure 8). The dark red area is the OTF-changed-area; its built environment has changed considerably from the OTF to non-OTF. The land use, transportation facilities, and travel behavior in these areas showed a fast-changing trend from 2010 to 2015. 

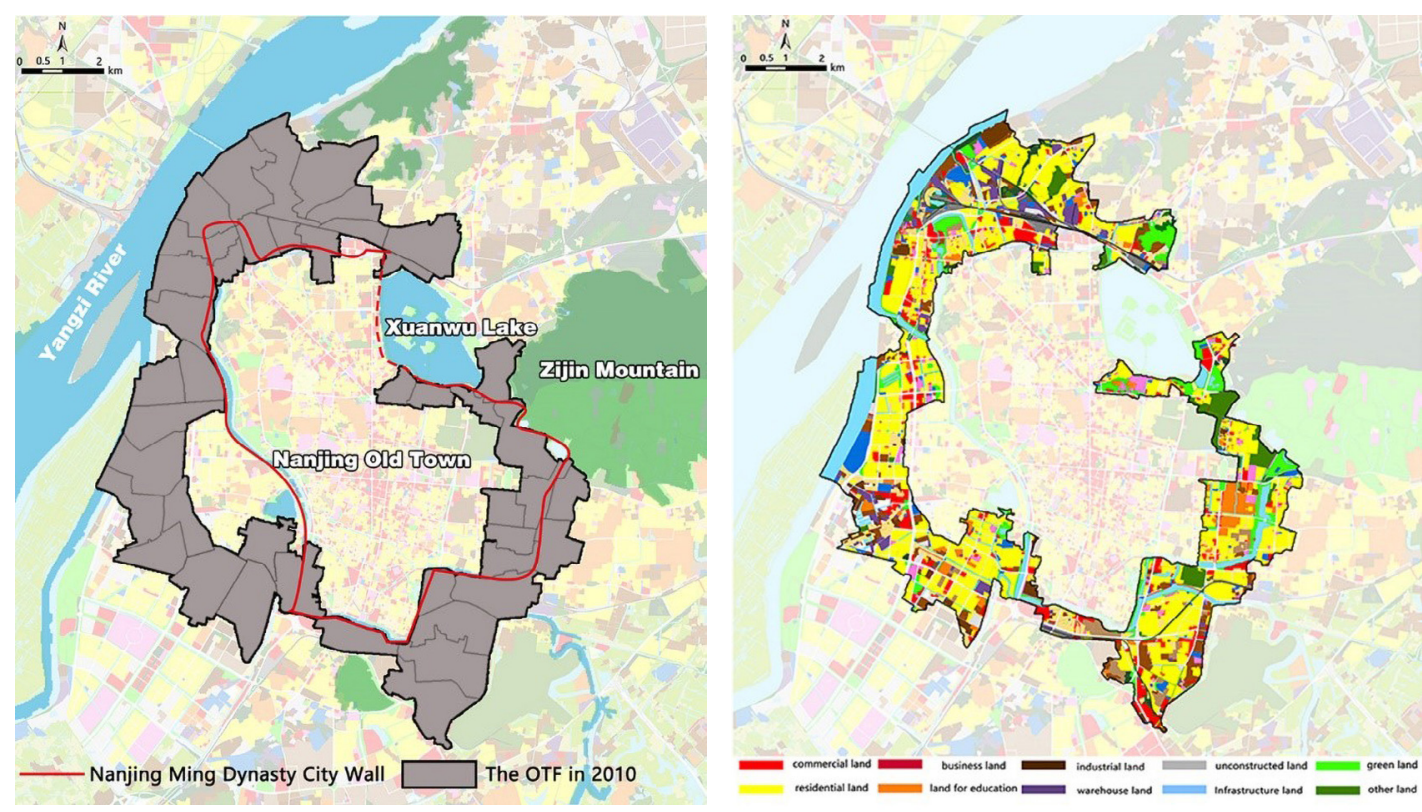

The two pictures are not aligned on the typesetting. Please adjust it to the right position.

Figure 6. Recognition of old town fringe in 2010
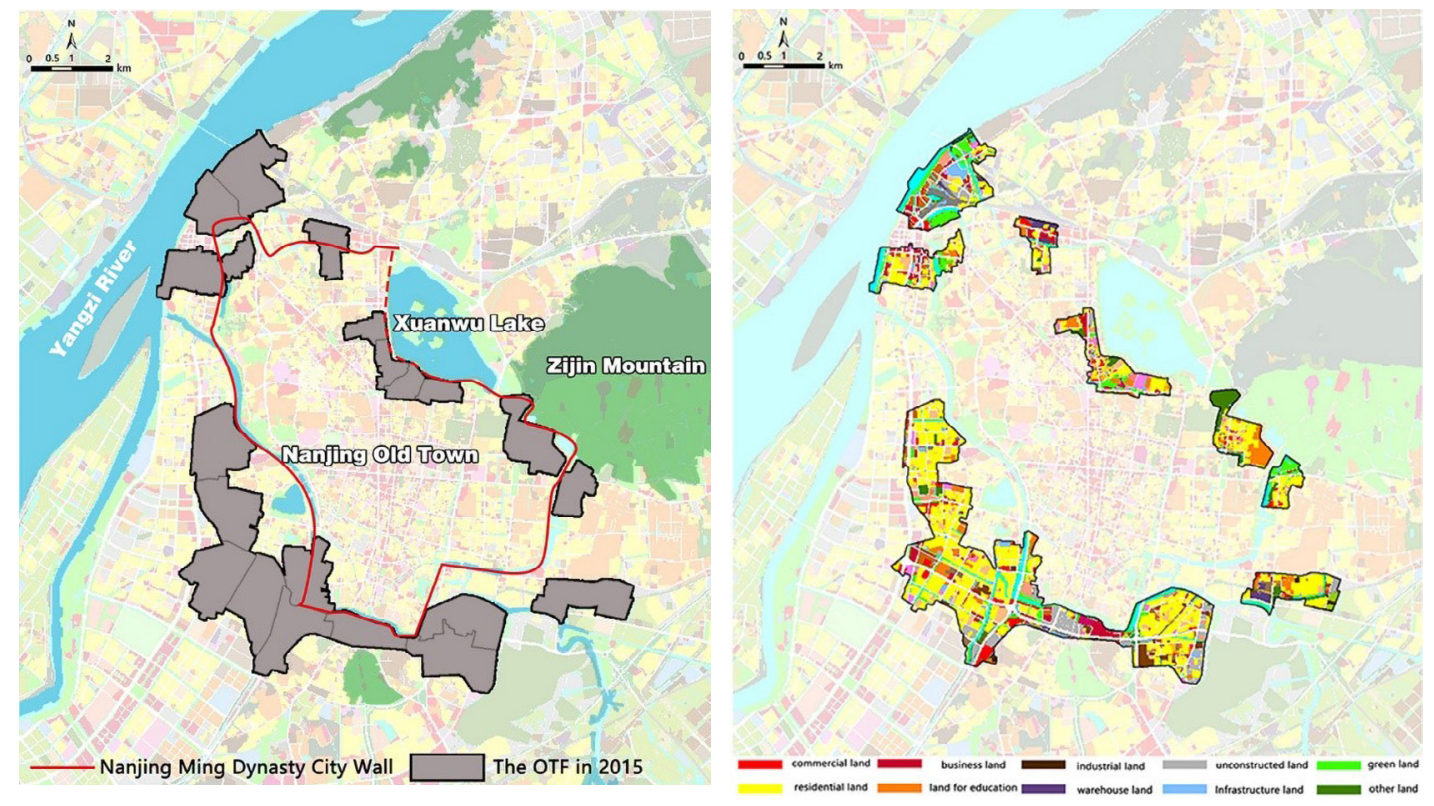

Figure 7. Recognition of old town fringe in 2015 


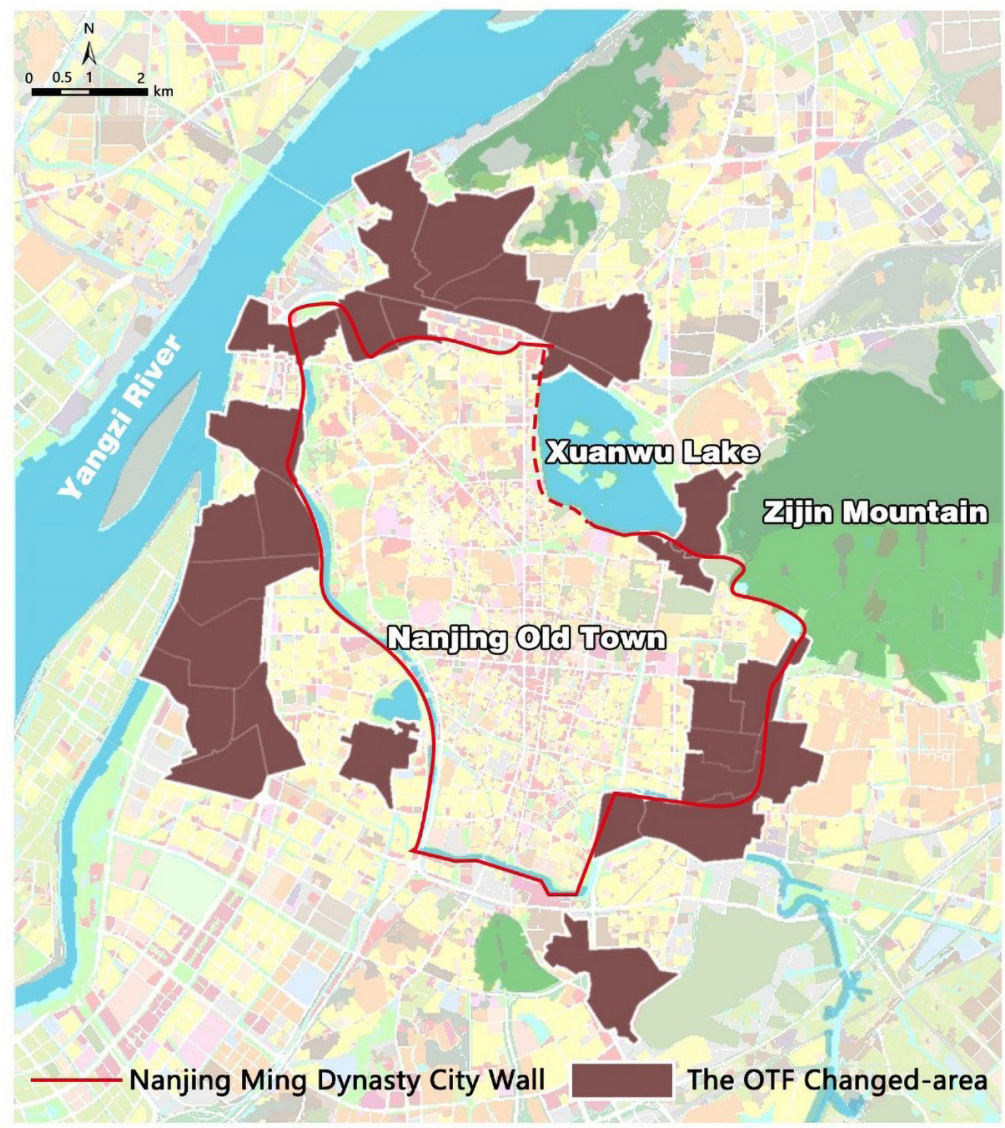

Figure 8. Changes of old town fringe from 2010 to 2015

\subsection{Changes in the old town fringe}

According to the range of the OTF in Figure 7 and Table 3, the built environment index data of all TAZs in this area were calculated (e.g., Table 3). According to this range, two-year travel data of residents in this region were screened out. From 2010 to 2015 the land use, transportation facilities, and travel behavior in the changed areas showed a rapidly changing trend (e.g., Table 4).

In terms of land use, the structure in this region has been greatly adjusted; commercial land and park green space has greatly increased, the former by more than $50 \%$. Conversely, residential land, public service land, and industrial land have decreased. Among them, residential land and public service facilities decreased by $0.15 \mathrm{~km}^{2}$ and $1.5 \mathrm{~km}^{2}$, respectively, while industrial land was reduced by half, around $1.1 \mathrm{~km}^{2}$. In terms of spatial development intensity, the region has evolved from low-intensity development to medium-high-intensity development. The mean volume ratio increased from 0.95 to 1.03. The significant decrease in building density indicates that high-rise buildings are gradually replacing middle and bottom floors. The average and variance of job-housing ratios have greatly decreased indicating an unbalanced trend which may be related to some factories in the region being relocated. 
Table 3. Indicators of built environment for changes of old town fringe

\begin{tabular}{|c|c|c|c|c|c|c|c|c|c|}
\hline \multicolumn{2}{|c|}{ Built environment variable } & \multicolumn{4}{|l|}{2010} & \multicolumn{4}{|l|}{2015} \\
\hline & & \multirow[t]{2}{*}{ Mean } & \multirow{2}{*}{$\begin{array}{l}\text { Standard } \\
\text { Deviation }\end{array}$} & \multicolumn{2}{|l|}{ Range } & \multirow[t]{2}{*}{ Mean } & \multirow{2}{*}{$\begin{array}{l}\text { Standard } \\
\text { Deviation }\end{array}$} & \multicolumn{2}{|c|}{ Range } \\
\hline & & & & $\operatorname{Max}$ & Min & & & $\operatorname{Max}$ & Min \\
\hline \multirow[t]{3}{*}{ Density } & Building Density & 0.28 & 0.06 & 0.35 & 0.10 & 0.23 & 0.13 & 0.82 & 0.04 \\
\hline & Plot Ratio & 0.95 & 0.62 & 3.76 & 0.15 & 1.03 & 0.60 & 3.76 & 0.11 \\
\hline & $\begin{array}{l}\text { Road Network } \\
\text { Density }\left(\mathrm{m} / \mathrm{k} \mathrm{m}^{2}\right)\end{array}$ & 4.11 & 1.75 & 6.75 & 0.55 & 5.37 & 1.85 & 8.38 & 1.77 \\
\hline \multirow[t]{3}{*}{ Diversity } & $\begin{array}{l}\text { Land-Use } \\
\text { Diversity }\end{array}$ & 6.25 & 1.00 & 8 & 4 & 5.82 & 0.94 & 8 & 4 \\
\hline & Land-Use Mix & 0.73 & 0.10 & 0.93 & 0.59 & 0.66 & 0.11 & 0.82 & 0.40 \\
\hline & Job-housing Ratio & 1.58 & 3.82 & 20.42 & 0.06 & 0.56 & 0.65 & 2.86 & 0.05 \\
\hline Design & $\begin{array}{l}\text { Number of } \\
\text { Signal-controlled } \\
\text { Intersections }\end{array}$ & 3.61 & 3.28 & 14 & 0 & 3.14 & 2.72 & 10 & 0 \\
\hline \multirow[t]{2}{*}{$\begin{array}{l}\text { Destination } \\
\text { Accessibility }\end{array}$} & $\begin{array}{l}\text { Straight-line } \\
\text { Distance }(\mathrm{km})\end{array}$ & 4937.04 & 1218.77 & 7373 & 2910 & 4937.04 & 1218.77 & 7373 & 2910 \\
\hline & $\begin{array}{l}\text { Shortest Distance } \\
(\mathrm{km})\end{array}$ & 7.68 & 2.20 & 12 & 4 & 7.07 & 1.91 & 10.7 & 3.6 \\
\hline \multirow[t]{2}{*}{$\begin{array}{l}\text { Distance- } \\
\text { to-transit }\end{array}$} & $\begin{array}{l}\text { Subway Coverage } \\
(\mathrm{R}=1000 \mathrm{~m})\end{array}$ & 0.24 & 0.15 & 1.00 & 0 & 0.41 & 0.42 & 1.00 & 0 \\
\hline & $\begin{array}{l}\text { Bus Coverage } \\
(\mathrm{R}=300 \mathrm{~m})\end{array}$ & 0.79 & 0.12 & 1.00 & 0.58 & 0.79 & 0.12 & 1 & 0.56 \\
\hline
\end{tabular}

There have been some changes in population composition and travel characteristics in the area (Table 4). The percentage of women as part of the demographic composition of the population has increased. The ratio of men to women tends to balance. In both 2010 and 2015, young and middle-aged people aged 30-49 have made up most of the sample population in this area. From 2010 to 2015, there was a general increase in the proportion of people over the age of 40 , from $28.26 \%$ to $53.95 \%$. Among this group, the proportion of people over the age of 60 more than tripled, showing a certain degree of aging in this region. In terms of occupations, the two-year sample population is mainly commuters, including the categories of Worker, Service staff, Civil servant, Self-employed, Retiree, and Others. The proportion of retirees and other occupations has increased, while the proportion of students and workers has decreased. The education level of the region's population has increased, with the proportion of persons in college, undergraduate, graduate, and higher education more than doubling. In terms of travel behavior, the main changes were travel structure and travel time. A total of 945 valid travel samples were screened out in 2010, accounting for $21.15 \%$ of all travel data in the OTF in 2010. A total of 2,243 valid travel samples were screened out in 2015 , accounting for $38.43 \%$ of all travel data in the OTF in 2015. From 2010 to 2015, the average travel time of residents in the area decreased by $6.3 \%$. In addition, the proportion of public travel increased by nearly double, from $20.30 \%$ to $38.44 \%$. Vehicle travel increased by $15.5 \%$, but slow travel decreased by $33.1 \%$. Generally speaking, the proportion of public travel of residents in this area has increased significantly. With the improvement of space and facilities, the mode of residents' travel in this area has changed from mobile travel to public travel. 
Table 4. Individual characteristics and travel characteristics for changes of old town fringe

\begin{tabular}{|c|c|c|c|c|c|c|}
\hline \multirow[t]{2}{*}{ Variable } & \multirow[t]{2}{*}{ Description } & \multirow[t]{2}{*}{ Sign } & Frequency & Percent & Frequency & Percent \\
\hline & & & \multicolumn{2}{|l|}{2010} & \multicolumn{2}{|l|}{2015} \\
\hline \multicolumn{7}{|c|}{ Individual characteristics } \\
\hline \multirow[t]{2}{*}{ Gender } & Male & GEN & 675 & $71.43 \%$ & 1033 & $46.05 \%$ \\
\hline & Female & & 270 & $28.57 \%$ & 1210 & $53.95 \%$ \\
\hline \multirow[t]{8}{*}{ Age } & $6-14$ & AGE & 117 & $12.38 \%$ & 175 & $7.80 \%$ \\
\hline & $15-19$ & & 66 & $6.98 \%$ & 76 & $3.39 \%$ \\
\hline & $20-25$ & & 78 & $8.25 \%$ & 122 & $5.44 \%$ \\
\hline & $25-29$ & & 135 & $14.29 \%$ & 182 & $8.11 \%$ \\
\hline & $30-39$ & & 282 & $29.84 \%$ & 478 & $21.31 \%$ \\
\hline & $40-49$ & & 132 & $13.97 \%$ & 589 & $26.26 \%$ \\
\hline & $50-59$ & & 111 & $11.75 \%$ & 403 & $17.97 \%$ \\
\hline & $>60$ & & 24 & $2.54 \%$ & 218 & $9.72 \%$ \\
\hline \multirow[t]{9}{*}{ Occupation } & $\begin{array}{l}\text { Middle school stu- } \\
\text { dents \& Elementary } \\
\text { School Students }\end{array}$ & OCC & 180 & $19.05 \%$ & 226 & $10.08 \%$ \\
\hline & $\begin{array}{l}\text { College \& Graduate } \\
\text { Students }\end{array}$ & & 54 & $5.71 \%$ & 78 & $3.48 \%$ \\
\hline & Worker & & 192 & $20.32 \%$ & 263 & $11.73 \%$ \\
\hline & Service staff & & 99 & $10.48 \%$ & 229 & $10.21 \%$ \\
\hline & Civil servant & & 210 & $22.22 \%$ & 538 & $23.99 \%$ \\
\hline & Self-employed & & 81 & $8.57 \%$ & 172 & $7.67 \%$ \\
\hline & Retiree & & 120 & $12.70 \%$ & 352 & $15.69 \%$ \\
\hline & Famer & & 0 & $0.00 \%$ & 21 & $0.94 \%$ \\
\hline & Others & & 9 & $0.95 \%$ & 364 & $16.23 \%$ \\
\hline \multirow{2}{*}{$\begin{array}{l}\text { Have driving } \\
\text { license }\end{array}$} & Yes & HDL & 348 & $36.83 \%$ & 828 & $36.91 \%$ \\
\hline & No & & 597 & $63.17 \%$ & 1415 & $63.09 \%$ \\
\hline \multirow[t]{4}{*}{ Educational level } & $\begin{array}{l}\text { Junior high school and } \\
\text { below }\end{array}$ & & 417 & $44.13 \%$ & 447 & $19.93 \%$ \\
\hline & $\begin{array}{l}\text { High School and } \\
\text { Secondary School }\end{array}$ & & 330 & $34.92 \%$ & 803 & $35.80 \%$ \\
\hline & $\begin{array}{l}\text { College and under- } \\
\text { graduate }\end{array}$ & & 189 & $20.00 \%$ & 949 & $42.31 \%$ \\
\hline & Master and above & & 9 & $0.95 \%$ & 44 & $1.96 \%$ \\
\hline \multicolumn{7}{|l|}{ Travel characteristics } \\
\hline \multirow[t]{3}{*}{ Travel mode } & Walking and Cycling & $\mathrm{TM}$ & 621 & $62.54 \%$ & 1489 & $65.71 \%$ \\
\hline & Public transport & & 201 & $20.24 \%$ & 365 & $16.11 \%$ \\
\hline & motor vehicle & & 171 & $17.22 \%$ & 412 & $18.18 \%$ \\
\hline \multirow{5}{*}{$\begin{array}{l}\text { Time consumption } \\
(\mathrm{min})\end{array}$} & $0-15$ & TC & 132 & $13.29 \%$ & 728 & $32.13 \%$ \\
\hline & $15-30$ & & 381 & $38.37 \%$ & 647 & $28.55 \%$ \\
\hline & $30-60$ & & 120 & $12.08 \%$ & 327 & $14.43 \%$ \\
\hline & $60-90$ & & 231 & $23.26 \%$ & 319 & $14.08 \%$ \\
\hline & $>90$ & & 129 & $12.99 \%$ & 245 & $10.81 \%$ \\
\hline \multicolumn{3}{|c|}{ Average Time consumption (min) } & 50.62 & & 23.43 & \\
\hline
\end{tabular}




\subsection{Modeling results}

Taking the mode of motor vehicles as reference, the logit models of 2010 and 2015 were established for walking and cycling, and public transport, respectively.

Considering collinear problems exist between "Road Network Density" and "Number of Signalcontrolled Intersections," Road Network Density and "Shortest Distance," "Land-Use Diversity" and "Land-Use Mix," Road Network Density and Land-Use Diversity variables were excluded in the study. Building Density, Plot Ratio, Land-Use Mix, Job-housing Ratio, Number of Signal-controlled Intersections, Straight-line Distance, Shortest Distance, Bus Coverage, and Subway Coverage were eventually incorporated into the model of the built environment variables. The socioeconomic attribute variables of residents include gender, age, occupation, driving license, and education level. Females were the reference variable of gender. The age group was divided into four categories: children (6-14 years old), teenagers (15-24 years old), middle-aged (25-50 years old), and the elderly (over 50 years old). Children (6-14 years old) were regarded as the reference variable. The professions were grouped into four categories: students; commuters (including workers, staff, civil servants, service personnel, etc.); retired and others; private; and self-employed. Private and self-employed were considered the reference variable. Education level was divided into four categories, namely, junior high school and below; senior high school and technical secondary school; junior college and undergraduate; and master and above. Junior high school and below was the reference. The category of driving license regarded no driving license as a reference variable for having a driver's license. The results are shown in Table 5 and Table 6.

From the perspective of overall performance, with reference to the behavior of choosing motor vehicles, from 2010 to 2015, the significance of factors in promoting residents to choose walking, cycling, or public transit has changed. Moreover, there are three different dynamic characteristics of this change in significant correlation: (1) the correlation of factors is significant is stable in 2010 and 2015; (2) the correlation of factors is significant in 2010, but not significant in 2015; (3) the correlation of factors is not significant in 2010, but significant in 2015. This paper discusses these three points, respectively. 
Table 5. Model results of non-motorized travel modes (motor vehicle as reference)

\begin{tabular}{|c|c|c|c|c|}
\hline \multirow[t]{2}{*}{ Impact factor } & \multicolumn{2}{|l|}{2010} & \multicolumn{2}{|l|}{2015} \\
\hline & B & $\exp (B)$ & B & $\exp (B)$ \\
\hline Number of Signal-controlled Intersections & $0.214^{* * *}$ & $1.238^{* * *}$ & $0.25^{* * *}$ & $1.284^{* * *}$ \\
\hline Shortest Distance to Downtown & $-0.433^{* * *}$ & $0.649^{* * *}$ & $-0.285^{* *}$ & $0.752^{* *}$ \\
\hline Plot Ratio & $-0.742^{* * *}$ & $0.476^{* * *}$ & $-1.371^{* *}$ & $0.254^{* *}$ \\
\hline $\begin{array}{l}\text { Other Occupations ("Private and Self-employed" } \\
\text { as reference) }\end{array}$ & $4.432^{* * *}$ & $84.091^{* * *}$ & $0.759^{* * *}$ & $2.136^{* * *}$ \\
\hline $\begin{array}{l}\text { Master and Above ("Junior high school and below" } \\
\text { as reference) }\end{array}$ & $-21.981^{* * *}$ & $0^{* * *}$ & $-2.049^{* * *}$ & $0.129^{* * *}$ \\
\hline Driving License ("No Driving License" as reference) & $0.738^{*}$ & $2.091^{*}$ & $-1.245^{* * *}$ & $0.288^{* * *}$ \\
\hline Building Density & $-14.221^{* * *}$ & $0^{* * *}$ & 2.641 & 14.024 \\
\hline Land-Use Mix & $-5.98^{* * *}$ & $0.003^{* * *}$ & 0.861 & 2.365 \\
\hline $\begin{array}{l}\text { Junior College and Undergraduate ("Junior high } \\
\text { school and below" as reference) }\end{array}$ & $-1.898^{* * *}$ & $0.15^{* * *}$ & -2.45 & 0.783 \\
\hline Bus Coverage & -0.805 & 0.447 & $2.295^{* * *}$ & $9.923^{* * *}$ \\
\hline Male ("Female" as reference) & 0.225 & 1.253 & $-1.047^{* * *}$ & $0.351^{* * *}$ \\
\hline Elderly (“Children" as reference) & 13.271 & 579845.4 & $1.769^{* * *}$ & $5.864^{* * *}$ \\
\hline Straight-line Distance & 0 & 1 & $0^{* *}$ & $1^{* *}$ \\
\hline Job-housing Ratio & -0.014 & 0.986 & -0.083 & 0.92 \\
\hline Subway Coverage & -0.417 & 0.659 & 1.113 & 0.227 \\
\hline Teenagers (“Children” as reference) & -0.073 & 0.93 & -0.219 & 0.804 \\
\hline Middle-aged (“Children” as reference) & 1.086 & 2.962 & -0.18 & 0.835 \\
\hline Students ("Private and Self-employed" as reference) & -0.061 & 0.94 & -0.013 & 0.987 \\
\hline $\begin{array}{l}\text { Commuters ("Private and Self-employed" as refer- } \\
\text { ence) }\end{array}$ & 0.04 & 1.041 & 0.049 & 1.05 \\
\hline $\begin{array}{l}\text { Senior High School and Technical Secondary } \\
\text { School ("Junior high school and below" as refer- } \\
\text { ence) }\end{array}$ & 0.006 & 1.006 & 0.367 & 1.443 \\
\hline
\end{tabular}

*significant at 0.1 level

**significant at 0.05 level

***significant at 0.001 level

Table 6. Model results of public transit travel modes (motor vehicle as reference)

\begin{tabular}{|c|c|c|c|c|}
\hline \multirow[t]{2}{*}{ Impact factor } & \multicolumn{2}{|l|}{2010} & \multicolumn{2}{|l|}{2015} \\
\hline & B & $\exp (B)$ & B & $\exp (B)$ \\
\hline Shortest Distance to Downtown & $-0.597^{* * *}$ & $0.55^{* * *}$ & $-0.247^{* *}$ & $0.781^{* *}$ \\
\hline $\begin{array}{l}\text { Commuters ("Private and Self-employed" as refer- } \\
\text { ence) }\end{array}$ & $1.274^{* *}$ & $3.577^{* *}$ & $0.43^{* *}$ & $1.538^{* *}$ \\
\hline
\end{tabular}




\begin{tabular}{|c|c|c|c|c|}
\hline \multirow[t]{2}{*}{ Impact factor } & \multicolumn{2}{|l|}{2010} & \multicolumn{2}{|l|}{2015} \\
\hline & B & $\exp (B)$ & B & $\exp (B)$ \\
\hline $\begin{array}{l}\text { Other Occupations ("Private and Self-employed" } \\
\text { as reference) }\end{array}$ & $4.9^{* * *}$ & $134.355^{* * *}$ & $0.664^{* * *}$ & $1.943^{* * *}$ \\
\hline Land-Use Mix & $-4.58^{* *}$ & $0.01^{* *}$ & 0.623 & 1.865 \\
\hline Teenagers ("Children" as reference) & $-1.596^{* * *}$ & $0.203^{* * *}$ & 0.182 & 1.199 \\
\hline Middle-aged (“Children” as reference) & $-1.725^{*}$ & $178^{*}$ & 0.179 & 1.196 \\
\hline $\begin{array}{l}\text { Junior College and Undergraduate ("Junior high } \\
\text { school and below" as reference) }\end{array}$ & $-1.861^{* * *}$ & $0.156^{* * *}$ & -0.019 & 0.981 \\
\hline Number of Signal-controlled Intersections & 0.066 & 1.068 & $0.117^{* * *}$ & $1.124^{* * *}$ \\
\hline Building Density & 2.202 & 9.048 & $-7.205^{* * *}$ & $0.001^{* * *}$ \\
\hline Plot Ratio & -0.05 & 0.952 & $1.241^{* *}$ & $3.461^{* *}$ \\
\hline Bus Coverage & 1.857 & 6.403 & $2.42^{* * *}$ & $11.248^{* * *}$ \\
\hline Male ("Female" as reference) & -0.859 & 0.424 & $-1.063^{* * *}$ & $0.346^{* * *}$ \\
\hline Elderly ("Children" as reference) & 32.95 & 2.041 & $1.675^{* * *}$ & $5.336^{* * *}$ \\
\hline $\begin{array}{l}\text { Senior High School and Technical Secondary } \\
\text { School ("Junior high school and below" as refer- } \\
\text { ence) }\end{array}$ & 0.236 & 1.266 & $0.481^{*}$ & $1.618^{*}$ \\
\hline $\begin{array}{l}\text { Master and Above ("Junior high school and below" } \\
\text { as reference) }\end{array}$ & -20.111 & 0 & $-0.771^{*}$ & $0.463^{*}$ \\
\hline Job-housing Ratio & 0.002 & 1.002 & 0.207 & 1.229 \\
\hline Subway Coverage & -0.814 & 0.443 & 0.227 & 1.255 \\
\hline Students (“Private and Self-employed” as reference) & -1.019 & 0.361 & 0.309 & 1.362 \\
\hline Driving License ("No Driving License" as reference) & 0.575 & 1.777 & -1.280 & 0.278 \\
\hline
\end{tabular}

*significant at 0.1 level

** significant at 0.05 level

***significant at 0.001 level

\section{Discussion}

\subsection{Influencing factors of walking and cycling in the OTF-changed area}

Table 5 shows the results of the regression model of citizens choosing walking and cycling in the OTFchanged area in 2010 and 2015, respectively, with motor vehicle travel mode as the reference.

(1) Compared with the choice of motor vehicle travel, residents' choice to walk or bicycle is steadily correlated with Number of Signal-controlled Intersections, Shortest Distance to Downtown, Plot Ratio, Other Occupations ("Private and Self-employed" as reference), Master and Above ("Junior high school and below" as reference), Driving License ("No Driving License" as reference) in 2010 and 2015. Positively related factors are Number of Signal-controlled Intersections, Other Occupations, and Driving License. Negative correlation factors include Shortest Distance to Downtown, Plot Ratio, and Master and Above. Other Occupations promoted the probability of residents choosing walking or cycling decreased significantly in 2015 (2010: $\left.\exp (B)=84.091^{* * *} ; 2015: \exp (B)=2.136^{* * *}\right)$. This was because the other occupations are more diverse, including retirees, farmers, freelancers, and so on. Therefore, the relevance of their travel choices and occupations is relatively unstable. In addition, we need to pay attention to the factor Driving License, which changed from a positive correlation $\left(\mathrm{B}=0.738^{*}\right)$ to a negative correlation $\left(\mathrm{B}=-1.245^{* * *}\right)$. Sur- 
vey data show that the two-year driving license ownership rate is basically unchanged, both years being $36 \%$. This is mainly due to the increase in residents' income in 2015. Compared with 2010, rates of car ownership and real utility increased significantly among residents in 2015. Therefore, in 2015 residents with driving licenses were increasingly willing to choose a car to travel, compared to walking and cycling.

(2) Compared with the choice of motor vehicle travel, residents' choice to walk or bicycle was negatively correlated with factors Building Density, Land-Use Mix, and Junior College and Undergraduate ("Junior high school and below" as reference) in 2010, but not in 2015. Building Density in 2010 (B $=-14.221^{* * *}$ ) was significantly negatively related to the promotion of walking and cycling as popular choices. Many studies have found that high-density built environments are not conducive to walking or cycling. However, in 2015, the factor Building Density ( $\mathrm{B}=2.641$ ) was no longer relevant to residents' choice to walk and cycle. This is because in this period of urban development and construction, the control of building density and the design of the pedestrian system cannot guarantee coordination at all times. The study found that in 2010, the higher the mix of land use, the more willing residents were to choose motor vehicles instead of walking or cycling. In 2015, Land-Use Mix is no longer relevant to residents' choice to walk and cycle. The index of the degree of mixing in this study is the degree of mixing in the horizontal direction. However, from 2010 to 2015, cities gradually attached importance to the functional mix of vertical space. So the level of Land-Use Mix is no longer a significantly related indicator.

(3) Compared with the choice of motor vehicle travel, residents' choice to walk or bicycle was correlated with factors Bus Coverage, Male ("Female" as reference), Elderly ("Children" as reference), and Straightline Distance in 2015, but not in 2010. Among the factors that are positively related to residents' choice of walking or cycling are Bus Coverage, Elderly, and Straight-line Distance. From 2010 to 2015, not only did the coverage rate of public transit in the main urban area of Nanjing increase but the total number of public transit operations increased by almost $30 \%$. This is because the construction of a public transit system is mostly synchronous with the construction of a walking and cycling system. Measures such as shortening the route distance from a residential area to the public transportation station, optimizing the pedestrian route to the station, and arranging a non-motor vehicle traffic transfer in combination with the station have greatly improved the travel environment for those walking and cycling. That is, these measures have greatly encouraged people to choose non-motor vehicle travel. It is also worth noting the significant correlation changes in the factor Males, although the proportion of males in the sample population in the changed area in 2015 was $25 \%$ less than that in the 2010 sample. The results of the model show that from 2010 to 2015, the factor Males presented a negative correlation, and exp (B) decreased from 1.253 to 0.351 . This is mainly because the average commute distance of males increased by 2.8 $\mathrm{km}$ in five years, which was more than that of women. Therefore, males are more reluctant to choose walking, cycling, or public transit and are more inclined to travel by motor vehicle. It can be seen that compared with females, males are less willing to choose walking and cycling to commute. Simple findings on the influence of gender on travel mode have been found in urban studies of Western countries (Commins \& Nolan, 2011). In addition, the factor Elderly changed from insignificant to significant. The proportion of the elderly in the 2015 sample increased by $13.4 \%$ compared with 2010 , which has greatly contributed to the significance of this factor. Likewise, with more attention being paid in recent years to fitness and health, walking and cycling as a beneficial means of travel for physical and mental health are being accepted by more and more elderly people.

\subsection{Influencing factors of public transport in the OTF-changed area}

Table 6 shows the results of the regression model of citizens choosing public transit in the OTF-changed area in 2010 and 2015, respectively, with motor vehicle travel mode as the reference. 
(1) Compared with the choice of motor vehicle travel, residents' choice of public transit is steadily correlated with Shortest Distance to Downtown, Commuters ("Private and Self-employed" as reference), and Other Occupations ("Private and Self-employed" as reference) in 2010 and 2015. The positive correlation factors are Commuters and Other Occupations. The negative correlation factor is Shortest Distance to Downtown. The closer the shortest distance to the downtown, the greater the willingness to choose walking and cycling. It can be seen from the results that the correlation probability of the factor Other Occupations in these two years has dropped significantly. Survey data show that the proportion of this group of people actually increased by $18.27 \%$. However, from the results in Table 6, we can see that exp (B) drops from 4.9 to 0.664 . Most of these respondents are freelancers. They have high requirements for travel comfort. Besides, the car ownership rate of this group of people has increased significantly in the five years from 2010 to 2015.

(2) Compared with the choice of motor vehicle travel, residents' choice to walk or bicycle is correlated with the factors Land-Use Mix, Teenagers (Children as reference), Middle-aged (Children as reference), Junior College and Undergraduate (Junior high school and below as reference) in 2010 but not in 2015. These factors correlated negatively in 2010. The study found that in 2010 and 2015, the Land-Use Mix factor's performance of relevance is consistent in inducing residents to walk or cycle and use public transit. This further confirms that the mixed degree of horizontal land use has gradually weakened the promotion of residents' choice of non-motorized travel, which shows that vertical land-use mix needs to be taken seriously. Future research may pay more attention to this issue and try to include it in the urban built environment assessment index.

(3) Compared with the choice of motor vehicle travel, residents' choice to walk or bicycle is correlated with eight factors in 2010 but not in 2015. These factors include Number of Signal-controlled Intersections, Building Density, Plot Ratio, Bus Coverage, Male ("Female" as reference), Elderly ("Children" as reference), Senior High School and Technical Secondary School ("Junior high school and below" as reference), Master and Above ("unior high school and below" as reference). The positive correlation factors are as follows: Number of Signal-controlled Intersections, Plot Ratio, Bus Coverage, Elderly, and Senior High School and Technical Secondary School. The changes in the relevance of factors (Elderly, Senior High School and Technical Secondary School, Master and Above) in promoting residents' choice of public transit are consistent with walking and cycling. Meanwhile, the correlation of Building Density is the opposite. From Table 6, we can see that, compared with the choice of motor vehicle, the B value for walking and cycling changed from -14.221 to 2.641 . In terms of promoting public transit, the B value changed from 2.202 to -7.205 . This shows that the building density in 2010 has not contributed to the promotion of public transit, but there has been a negative correlation since 2015. According to the data on foundation construction, the overall building density in this area increased in 2015. Compared with 2010, people in 2015 preferred to travel by car, which was related to the built environment given the reduced spatial comfort of high-density blocks; high density brings about an unfriendly travel experience, and thus motor vehicles are a quicker way to reach a destination. Consistent with the findings in Table 6, the factors Bus Coverage and Elderly gradually show significant correlation. On the one hand, from 2010 to 2015, the planning and construction of the Nanjing road network was promoted, and the increase in bus shifts and the optimization of routes, as well as an increase in station coverage, have created better travel conditions. The convenience of facilities means that people prefer to choose public transportation. On the other hand, the proportion of elderly persons in this changing region has increased significantly in the past five years. More elderly people have begun to pay attention to outdoor sports and neighborhood exchanges. Their travel needs are gradually increasing and are diversified. In this social and family atmosphere in China, most of the elderly will take on some family duties such as buying vegetables and collecting children from school (Feng, 2017). With the gradual optimization of Nanjing's public trans- 
port network and the ongoing improvement of the coverage rate, the policy of providing free transport for elderly persons is fully covered. To some extent, this encourages them to choose public transit.

\section{Conclusion}

Unlike studies on the relationship between travel behavior and space, this study pays special attention to areas with significant changes in the OTF. In addition, unlike the previous static model construction, we pay more attention to the change of the travel and spatial relationship in the urban dynamic development area. After a comparative study in 2010 and 2015, a two-year model was established for cross-comparison and verification. This paper further explores the influence mechanism and evolution rule of the built environment and travel behavior in the process of dynamic change over time under the background of urban structure change and provides a possible focus for the urban renewal and traffic optimization of the old urban fringe.

In this study, multivariate data were first used to identify the scope of the old urban fringe areas in the past two years, and then the travel data and built environment data of the changed areas in the old urban fringe areas were screened and counted. Then, Multinomial Logit Models were used to evaluate the impact of the built environment and individual economic and social attributes of residents on the choice of travel modes. Finally, the significance of the factors influencing the two-year travel behavior was analyzed and compared, and the reasons for the differences were analyzed.

By building the models and comparing with motor vehicle travel, we found that related factors will change with the evolution of space in promoting residents' choice of non-motor-vehicle trips. This discovery allows us to look at the interaction mechanism between travel and space from a new perspective. For the fast-changing and unstable development in the fringe area of the old town, planning decisions for only one year's model results are one-sided. The study found that in promoting residents' choice of non-motor-vehicle transportation (walking, cycling, or public transit), factors like the Shortest Distance to the Downtown, and Other Occupations were both significant and positive in the past five years. Further, the significance is relatively stable; that is, it has not been affected by the changing nature of the OTF. However, the study found that from 2010 to 2015, most factors fluctuated in significance. It is found that the correlated factors of fluctuation are mainly social attribute factors, for example, education, gender, age, whether one has a driving license, etc. This is because, with the passage of time, people's concepts and life needs are changing, and lifestyles are also changing quickly. The requirements of space and travel for diverse populations are various. Planners should be keenly aware of the sensitivity of social attributes of this group of people. Starting from the needs of the people to gain insight into the spatial changes in the OTF will greatly help the development of the area. Therefore, in future research and practice, we need to focus on the impact of stable correlated factors (such as Shortest Distance to Downtown, Plot Ratio, Occupation, etc.) and factors whose correlation is increasing (such as Bus Coverage, Gender, Age, etc.). And the Land Mix factor needs to be considered from both vertical and horizontal perspectives. This will have certain significance and help for the future development of the old town fringe.

These findings provide a possible development direction for land-use planning and traffic optimization in the changing area of the OTF. In the process of the renewal of the old urban fringe area, it is necessary to pay attention to the traffic impact caused by the superposition of the Crowd Social Attribute factor, Urban Design factor, and Traffic Facility factor, and dynamically pay attention to the factors with significant influence, and influence change. (1) In terms of Social Attribute factors, we found that the higher their level of education, the more residents tend to choose non-motorized vehicles. Therefore, it is necessary to more strongly advertise green travel and enhance residents' awareness of environmental protection. (2) In terms of urban design factors, it is necessary to pay attention to the impact of the plot ratio. The lower the plot ratio, the more willing people are to choose non-motorized vehicles. In 
future planning, consideration should be given to improving the quality of the walking experience, for example, improving the connection between walking paths and other travel modes, adding corridors between high-rise buildings on the second floor, improving the continuity of walking, etc. (3) Meanwhile, in terms of traffic facility factors, increasing the bus coverage rate and the number of intersections can promote walking or cycling and the probable use of public transit. So the proportion of motor traffic in the OTF will be reduced, and the complex traffic pressure in this area will be alleviated.

The main contribution of this study is its focus on the mesoscale special dynamic zone in the OTF alternating zone. This article attempts to discover the changed area of OTF and then study the dynamic relationship between travel behavior and spatial dynamics in the staggered area. Advice on the development and transportation optimization of OTF can be found and proposed. This study provides comparative research for different years to understand the relationship between the built environment and travel behavior in areas undergoing significant changes. This paper also has certain shortcomings and limitations. Firstly, the accuracy with which the study divides the traffic communities TAZ needs to be improved, because the accuracy of the division of the traffic area directly affects the accuracy of the boundary recognition of the OTF. At present, the division of TAZ is mainly along the lines of the minor arterial roads. The size of the traffic community is mainly around 3,000 square meters and above. Therefore, there is a lack of related research on a single block scale. So we can increase the number of TAZ divisions to reduce the size of each TAZ in future research. In this way, the borders of the OTF can be made more precise. Secondly, the two-year comparative research used in this study is currently a household survey, although the study keeps the two-year house number as consistent as possible and reduces the population sample difference between two years. However, it is not really a follow-up survey of people. If the sample-invariant follow-up survey is adopted, it will greatly contribute to the study of the fringe area of the old city.

\section{Acknowledgement}

The research is jointly supported by National Natural Science Foundation of China (51678132, 71871057, 51778277, 51678130). 


\section{References}

Bohte, W., Maat, K., \& van Wee, B. (2009). Measuring attitudes in research on residential self-selection and travel behavior: A review of theories and empirical research. Transport Reviews, 29(3), 325-357.

Bowman, J. L., \& Ben-Akiva, M. E. (2001). Activity-based disaggregate travel demand model system with activity schedules. Transportation Research, Part A (Policy and Practice), 35(1), 0-28.

Cao, X., Mokhtarian, P. L., \& Handy, S. L. (2007). Do changes in neighborhood characteristics lead to changes in travel behavior? A structural equations modeling approach. Transportation, 34(5), $535-556$.

Cervero, R., \& Murakami, J. (2010). Effects of built environments on vehicle miles traveled: Evidence from 370 US urbanized areas. Environment and Planning A, 42(2), 400-418.

Cervero, R., \& Kockelman, K. (1997). Travel demand and the 3Ds: Density, diversity, and design. Transportation Research Part D: Transport and Environment, 2(3), 199-219.

Chen, X., Wang, S., Shi, C., Wu, H., Zhao, J., \& Fu, J. (2019). Robust ship tracking via multi-view learning and sparse representation. Journal of Navigation, 72(1), 176-192.

Chen, X., Li, Z., Wang, Y., Tang, J., Zhu, W., Shi, C., \& Wu, H. (2018). Anomaly detection and cleaning of highway elevation data from Google Earth using ensemble empirical mode decomposition. Journal of Transportation Engineering, Part A: Systems, 144(5), 04018015.

Chen, Y. Q. (1996). On the urban-rural ecotone and its characteristic and function. Economic Geography, 16(3),27-31.

Christian, H., Knuiman, M., Divitini, M., Foster, S., Hooper, P., ...Giles-Corti, B. (2017). A longitudinal analysis of the influence of the neighborhood environment on recreational walking within the neighborhood: Results from RESIDE. Environmental Health Perspectives, 125 (7), 077009.

Commins, N., \& Nolan, A. (2011). The determinants of mode of transport to work in the Greater Dublin Area. Transport Policy, 18(1), 259-268.

Ding, C., Wang, D., Liu, C., Zhang, Y., \& Yang, J. (2017). Exploring the influence of built environment on travel mode choice considering the mediating effects of car ownership and travel distance. Transportation Research Part A: Policy and Practice, 100, 65-80.

Ettema, D., \& Nieuwenhuis, R. (2017). Residential self-selection and travel behavior: What are the effects of attitudes, reasons for location choice and the built environment? Journal of Transport Geography, 59, 146-155.

Feng, J. (2017). The influence of built environment on travel behavior of the elderly in urban China. Transportation Research Part D: Transport and Environment, 52, 619-633.

Feng, J., Dijst, M., Wissink, B., \& Prillwitz, J. (2014). Understanding mode choice in the Chinese context: The case of Nanjing Metropolitan Area. Journal of Economic \& Social Geography, 105(3), 3.

Gu, C. L., Chen, T., \& Ding, J. H. (1993). Study on the characteristics of the border area of China's big cities. Geography Journal, 48(4), 317-328.

$\mathrm{Gu}, \mathrm{C} . \mathrm{L} ., \mathrm{\&}$ Chen, T. (1995). The study of the urban fringes in China. Beijing, China: Science Press.

Handy S. L., Boarnet, M. G., Ewing, R., Killingsworth, R. E. (2002), How the built environment affects physical activity: Views from urban planning. American Journal of Preventive Medicine, 23(2 Suppl), 64-73.

Khan, S., Maoh, H., Lee, C., \& Anderson, W. (2014). Towards sustainable urban mobility: Investigating non-work travel behavior in a sprawled Canadian City. International Journal of Sustainable Transportation, 10(4), 141224081028003.

Lawrence, D. F., Schmid, T. L., Sallis, J. F., Chapman, J., Saelens, B. E. (2004). Linking objectively measured physical activity with objectively measured urban form. American Journal of Preventive 
Medicine, 28(2), 117-125.

Lu, Y., Xiao, Y., \& Ye, Y. (2016). Urban density, diversity and design: Is more always better for walking? A study from Hong Kong. Preventive Medicine, 2016, $103 \mathrm{~S}$.

Maat, K., \& Timmermans, H. J. (2009). A causal model relating urban form with daily travel distance through activity/travel decisions. Transportation Planning and Technology, 32(2), 115-134.

Manaugh, K., Miranda-Moreno, L. F., \& El-Geneidy, A. M. (2010). The effect of neighborhood characteristics, accessibility, home-work location, and demographics on commuting distances. Transportation, 37(4), 627-646.

Mu, X. D., Liu, H. P. (2010). The definition method of urban fringe based on the theory of regional urban structure and remote sensing monitoring. International Conference on Remote Sensing.

Munshi, T. (2016). Built environment and model choice relationship for commute travel in the city of Rajkot, India. Traffic Research Part D Traffic, 44, 239-253.

Naveen, E., Vincent, C., \& Ahmed, M. E. (2002). Travel mode choice and transit route choice behavior in Montreal: Insights from McGill University members commute patterns. Public Transport, 4(2), 129-149.

Rong, Y. F., Guo, S. W., \& Zhang, Y. F. (2011). A summary of research on urban fringes. Journal of Urban Planning, 04, 93-100.

Schwanen, T., \& Mokhtarian, P. L. (2005). What affects commute mode choice: Neighborhood physical structure or preferences toward neighborhoods? Journal of Transport Geography, 13(1), 0-99.

Schwanen, T., Dieleman, F. M., \& Dijst, M. (2004). The impact of metropolitan structure on commute behavior in the Netherlands: A multilevel approach. Growth and Change, 35(3), 304-333.

Shiftan, Y., \& Barlach, Y. (2002). Effect of employment site characteristics on commute mode choice. Transportation Research Record. https://doi.org/10.3141/1781-03

Sun, G. (2014). Exploring the influence of changes to the built environment on walking behavior: A natural experiment within a university campus in Hong Kong ( $\mathrm{PhD}$ dissertation and master's thesis).

Ta, N., Chai, Y., Zhang, Y., \& Sun, D. (2017). Understanding job-housing relationship and commuting pattern in Chinese cities: Past, present and future. Transportation Research Part D: Transport and Environment, 52, 562-573.

van Wee, B. (2009). Self-selection: A key to a better understanding of location choices, travel behavior and transport externalities? Transport Reviews, 29(3), 279-292.

Vandersmissen, M. H., Villeneuve, P., \& Thériault, M. (2003). Analyzing changes in urban form and commuting time. The Professional Geographer, 55(4), 446-463.

Wang, Y., \& Gu, C. L. (2017). Study on the delineation of urban elastic growth boundary based on grid analysis - a case study of Suzhu. City Planning Review, 41(3), 25-30.

Wang, H. Y., Zhang, X. C., Kang T.J., et al. (2011). Urban fringe division and feature analysis based on the multi-criterion judgment. Journal of Natural Resources, 26(4), 703-714.

Wei, Z., Yu, Q. P., De. W., et al. (2012) Travel behavior change after the introduction of public bicycle systems: A case study of Minhang District, Shanghai. Urban Planning Forum, 43(5), 76-81.

Yang, Z. W., \& Xu, Y. (2012). Evolution of spatial structure of contemporary Suzhou border areas based on multi-interest. Journal of Urban Planning, 03, 37-43.

Ye, R., \& Titheridge, H.. (2016). Satisfaction with the commute: The role of travel mode choice, built environment and attitudes. Transportation Research Part D: Transport and Environment, 52(B), 535547.

Zegras, C. (2010). The built environment and motor vehicle ownership and use: Evidence from Santiago de Chile. Urban Studies, 47(8), 1793-1817.

Zhou, W. Z., Li, Q., Wang, N., Li, Z. B., Pu, Z. Y., \& Wang Q. (2019). Old town fringe recognition 
and travel characteristics analysis based on multi-source data fusion. Advances in Mechanical Engineering, 11(2),1-15.

Zhou, W. Z. (2003). Study on the spatial development mechanism of the old city center under traffic guidance. Nanjing, China: Southeast University Press. 